Research Article

Open Access

Helen Kim*

\title{
Being "Other" in Berlin: German Koreans, Multiraciality, and Diaspora
}

https://doi.org/10.2478/jcgs-2018-0007

\begin{abstract}
Germany is considered a relatively recent country where multiraciality has become a recognised phenomenon. Yet, Germany still considers itself a monoracial state, one where whiteness is conflated with "Germanness". Based on interviews with seven people who are multiracial (mostly Korean-German) in Berlin, this article explores how the participants construct their multiracial identities. My findings show that participants strategically locate their identity as diasporic to circumvent racial "othering". They utilise diasporic resources or the "raw materials" of diasporic consciousness in order to construct their multiracial identities and challenge racism and the expectations of racial and ethnic authenticity. I explored how multiracial experiences offer a different way of thinking about the actual doing and performing of diaspora.
\end{abstract}

Keywords: Citizenship; Post-Modernism; Environmental Citizenship; Identity; Waste Management.

\section{Introduction}

Multiracial ${ }^{1}$ people are often conceptualised as being cosmopolitan and progressive embodiments of a post-racial future (Haritaworn 2009). Particular multiracial bodies carry the symbol of being desirable, urban and transgressive without being threatening. While the discourse of multiraciality, both in academia and in popular culture, is one that often celebrates the transgressive state of multiracial "in-betweenness", the reality is that those who are or are perceived to be multiracial are still seen as out of place and "Other". The existence of a mixed-race population is a result of different migration and colonial histories in each society. Multiraciality is considered a relatively recent phenomenon in Germany (King-O'Rhiain et al. 2014). Relatedly, Germany has been considered (and considers itself) a monoracial state. The existence of a multiracial Korean population in Germany can be attributed to Germany's immigration policies that started in 1970. In 1970, an official economic agreement between the Federal Republic of Germany and the Republic of South Korea brought approximately 10,000 female nurse "guest workers" from Korea. Some of these guest workers returned to Korea, and many migrated to the USA and Canada, however, many chose to remain and settle in Germany. When the guest worker program ended in 1973, a move that was strongly supported by the German public, the intention was that these guest workers would return to their countries of origin. However, over the past 50 years, (West) Germany has received almost 30 million immigrants from around the world, including ethnic Germans from other parts of Europe, many of whom permanently settled in the country. While about 15 million of these immigrants were ethnic Germans, half were non-German nationals. Out of this, almost 3 million of these non-national guestworkers recruited

1 The term "multiracial" has become a preferred term in the US to refer to those with mixed ancestry. In the UK, "mixed race" is generally the preferred term. In this article, I have used both terms synonymously.

*Corresponding author: Helen Kim, Ph.D., University of Leeds, Leeds, United Kingdom, Email: h.kim2@leeds.ac.uk 
during these years ended up remaining in Germany (Green 2003). However, Germany has historically denied that it is a country of immigration (Wilpert 2010; Martin 1994) despite the fact that it has one of the highest immigration rates in Europe.

Terms such as Auslander (foreigner) are used to refer to those who are perceived as being "Other", and this can include Eastern Europeans, Turkish and Asians. Similarly, someone who is visibly non-white is often referred to as a person with a "migration background" (Nandi and Spickard 2014). While the concept of race tends to be avoided in Germany as it is associated with the country's Nazi past, whiteness is key to how Germans define themselves as belonging to the German nation. Those who are considered foreigners or descendants of migrants are often considered to be non-German as there is often a reluctance to recognise non-whites as Germans.

As is the case in all multicultural nations, racialised hierarchies position minority groups differently to the hegemony. Moreover, integrationist discourses are prevalent and central to how immigration, "race" and otherness are framed. Immigrants in Germany (and elsewhere) are often accused of failing to integrate into white, mainstream German society; however, certain immigrant groups are targetted more than others. East Asians in Germany are often perceived to be the "model minority" and have generally been considered to have integrated successfully into the German society. Similar to the Americans, Asians are often considered as "industrious", "hard working", "quiet" and "law abiding". In particular, the secondgeneration diaspora is often seen as being very successful and fully integrated into the German society, with high levels of economic and educational achievement. This positive stereotyping reinforces the view that East Asians are a homogenous and monolithic racial group, and obscures the fact that structural and individual forms of racism continue to shape East Asian experiences in Germany. At the same time, it is important to draw attention to the existence of the model minority stereotype because it reflects how racialised hierarchies position groups differently and how they confer privilege to certain groups based on the notion that "they" are more or less like "us".

Based on interviews done with seven people who are multiracial and whose heritage is both white German (mostly) and Korean in (mostly) Berlin, this article draws on a larger oral history project involving 25 Korean first- and second-generation diaspora in Germany. I conducted semi-structured interviews and ethnographic participation and observation within different spaces, including homes, festivals, outings and meetings in the spring, summer and autumn of 2015. The interviews were conducted in Berlin and other parts of Germany, primarily in the Nordrhein Westfalen region of Germany where many Koreans have settled permanently. A purposive sample was used with gatekeepers and where I used existing networks of family friends and associates. The first-generation interviewees were Koreans aged 60-75 years. The second-generation interviewees, who were all the children of the first-generation Koreans, were born and raised in Germany and aged 25-45 years.

This article aims to make a significant contribution to the study of multiraciality in Germany. A great deal of the research on mixed race has emerged from the US. In recent years, mixed race studies have emerged that focus on Latin America and the UK, but very little has been written on mixed race in other parts of Europe, such as Germany. More specifically, there has been very little written on the Korean mixedrace population in Germany, which is significant given that there is a Korean community that has settled in Germany since the 1970s. Equally important, research on mixed race has addressed broader issues of race and ethnicity, but as yet, very few studies have been conducted that speak to larger questions of race and ethnicity in Germany (with a few exceptions). Furthermore, mixed race studies have often focused on racial groups contained within nation-state boundaries. Transnational and diasporic perspectives of mixedness and mixed-race identities are notably missing from the literature.

In this article, I address this gap in the literature by specifically focussing on the links between the shaping of a multiracial identity and the ways that transnational and diasporic connections shape these identities. This offers an original and under-researched perspective to the study of multiracial identities. It has been argued that multiracial people are often forced to choose only one ethnic or racial category even if they do not identify with a singular racial category (Aspinall and Song 2013). The focus on diasporic identity-making allows for the possibility of constructing alternative forms of identity that do not strictly adhere to binary categories of racialisation. 
Furthermore, I explore how multiracial participants develop diasporic connections and resources that challenge and resist their racialised positions in Germany. By focussing on the strategic deployment of these diasporic resources, this article explores how diaspora is lived through the doing and "becoming", highlighting the fact that diaspora is not something that we are but something that we do. It offers a more critical approach to diaspora that eschews it as a given or taken-for-granted descriptive category that also assumes connectedness or affinities based solely on ethnicity or race (Brubaker 2005; Alexander 2017). Instead, the focus on diasporic resources allows for diaspora to be treated as a set of practices that form a complex, strategic and deliberate "stance" (Alexander 2017). Diasporic resources suggest an active process of identity-making and, as such, are always fluid, temporal, partial and situated.

\section{Diaspora studies and diasporic resources}

Over the past few decades, diaspora as a concept and as an area of study has become widely used, to refer to almost any community or ethnic group living outside of their "homeland" (Brubaker 2005; Story and Walker 2015). Diaspora research spans across the social sciences and humanities disciplines. Within the social sciences, diaspora research has centred on the ways that people feel at home in their countries of settlement yet also make identifications outside of it (Walter 2001). It has been argued that diaspora is often concerned with the "intersections of home, memory, identity and belonging" (Blunt and Dowling 2006; 199). The work of Hall (1990, 2004), Gilroy (1993), Brah (1996, 1999) and Claire (2010) emphasises how diaspora has been about ways of belonging that circumvent the nation-state as the centre of these definitions. Equally important is in how conceptions of diaspora highlight the impossibility of drawing firm boundaries around racial and ethnic differences (Alexander 2010).

While earlier conceptions of diaspora might have been more about its use as a typological tool to point out grounded facts, this has given way to thinking about diaspora as a social process (Anthias 1998; Alexander 2010; Kalra, Kaur and Hutnyk 2005) or a "stance" (Alexander 2017) that offers a more critical theoretical engagement with difference. Understanding diaspora not just as a given category but as an active, self-fashioning and political "stance" becomes useful to understanding how participants in my study create and fashion diasporic affiliations and develop markers of identity in order to make certain claims about their identity, to strategically win space. This view of diaspora and, particularly, the view that diasporic claims are self-fashioned and strategic are highlighted within this article.

Furthermore, many scholars have emphasised the importance of identity as "becoming", of "home" being as much about the places of settlement as it is about remembering a past "homeland" (Brah 1996; Fortier et. al 2003). Through explorations of diasporic meanings of home, of belonging and of travel, researches on diaspora have offered important critiques of static and bounded notions of nation, ethnicity, community and race (Hall 1990; Alexander 2010; Brah 1996, Ellis 2015). My participants within this research, in their active self-fashioning of diasporic identities, help to challenge and contest these bounded notions of nation, ethnicity and race that determine "imagined communities" of people.

Further to this, diaspora studies interrogate the role of location in structural, material, and social and subjective terms. In particular, in this article, I use Brown's concept of "diasporic resources" or the "people and places, ideas, ideologies and iconographies associated with them" (Brown 1998). Brown argues that diasporic resources are not a concrete set of geographic realities but are, in fact, a set of social relations that are constructively enacted and are social spaces constructed "in tandem with racial formations" $(1998,297)$. Diaspora, through practices and resources, becomes a critical set of tools through which people navigate spaces and their own positions but always attendant to power relations. The importance of social and cultural practices, as well as place, to the construction of identities is especially useful to understanding how people do diaspora and under what conditions. Scholars who have thought about diaspora, and particularly diasporic communities outside the US, including Gilroy (1996), Brown (1998) and Campt (2002), focus on the active and strategic constructions of desire, community and identity in 
and through diaspora. Diasporic communities and relations are made and remade, rather than being just descriptive labels for ethnic or racial ties (Campt 2002, Alexander 2010).

Diaspora as a concept has been very useful in "critiquing fixity" (Brah 1996) in a myriad of ways. Understanding diaspora as a method has been used to complicate claims to a racial or ethnic authenticity, which are often based on fixed ideas of the "truth" of race and ethnicity. Diasporic identity-making works to dislodge and uproot fixed ideas of race, ethnicity and nation within their identity, or to put it another way, it is a "radical investment in the estrangement from race and nation" (James 2016). Work that focuses on the attachments and connections that form out of modes of diasporic belonging show how they are based on the notion that identities are more complex and porous, multi-layered and shifting (Hall 1992). Having said this, very few diaspora studies seem to focus on the intersections of diasporic formations and racialisation, with some notable exceptions (Gilroy 1993; 2000; 2004; Campt and Thomas 2008; Pierre 2008; Brown 1998; Parrenas and Siu 2007). Diaspora research allows for researchers to pay attention to how people push back against the fixity of racial categories by being able to strategically position themselves as subjects who are not tied or bound to their perceived racial and national identities. In so doing, diasporic identifications help to redefine the terms of belonging. In response, this article addresses how diasporic identification and racialisation intersect in contradictory ways. This article draws attention to the limits and the opportunities that diasporic modes of being and belonging have within an urban landscape to offer alternative modes of identification beyond strictly ethnic or racial identities. Furthermore, this article highlights how and under what circumstances the active construction of diaspora intersects with racemaking and racial formations in order to decouple race, nationality and belonging in Germany.

Equally important, diaspora studies have worked to ground diaspora within local spaces and places and have looked at how diasporic forms of belonging are rooted in actual, material connections within the "here" and "now" of the places of settlement rather than in the "there" and "back then" of the homeland. This work was responding to critiques of earlier work that tended to de-territorialise belonging and identity in an effort to theorise diaspora. However, in this article, I aimed to show how a return to the "there" of diasporic modes of identification and belonging for my participants is part of the active strategic imagining of diaspora. More recent work on diasporic identification, including Nadia Ellis' (2015) book, centre on the complex and shifting desires and attachments to here and "elsewhere" that are both imagined and material. Ellis stresses how a conception of the "elsewhere", not specifically tied to a specific geographic location, is central to the diasporic imagination.

In this article, I incorporated Ellis' framing of the "elsewhere" to explore how multiple "theres" becomes central to the lived experiences of a multiracial German-Korean diaspora. The active constructions of diasporic consciousness, located in part in the "elsewhere", help to make communities in these urban spaces because it is not about being tied to an ethnically specific sense of Koreanness. In contrast, the imagining of the "elsewhere" helps to construct an alternative transnational positioning that acts as a critical resource against being positioned as the racial "Other" in Germany.

\section{Diasporic belonging and the city}

Misu's mother is Korean, and her father is white German. She grew up in the outer suburbs of Berlin with her parents and her sister. She is 23 years old and had just graduated from Frei University, where she majored in Korean studies. She moved to Korea for six months and had just returned two months ago.

I start with Misu's story of her experiences of going to school and then university in Berlin. Misu talked about the way that the university programme opened up a new world for her, especially when it came to broaden her connections with others.

The people I met in Berlin at Frei University, maybe it's because they come from different cities in Germany, but there's a certain mind-set from people who go to different places and that's really appealing to me and I've always got this feeling that I didn't have that in school. How to explain this $1 / 4$ it's like when I was 15 I started to go out. I had this one friend Toni and we're still in contact. We would always go into the city and we would pick a club and we would go and listen to some amazing music. With her, you could go into the city and do exciting stuff and that's why I'm still good friends with her. With 
all the other people in school, they only wanted to go out to these suburban, boring places and the same places all the time. So, this is what I have in common with university people - with people who have a similar mind-set. You know, there were lots of students who were Vietnamese, Chinese and also a few half-Koreans like me, but I was also surprised at how many non-Korean students there were! This is also where I met my boyfriend, whose family comes from Vietnam.

The diverse make-up of the programme's student body reflected the existence of an urban multiculture in Berlin, where difference was actually lived and practiced in the everyday. Avtar Brah's conception of diaspora space outlines a useful framework to understand the importance of location to the existence of a lived urban multiculture in Berlin. Brah defined diaspora space as one of the "entanglements of genealogies of dispersion with those of 'staying put' where the native is as much the diasporean is the native" (1996, 181). The diaspora space is where boundaries between belonging and otherness and between "us" and "them" are less fixed and more porous. The programme at Frei University provided a diaspora space for these students where "native" and "diasporean" encounters, connections and friendships became entangled, crossed and blurred.

Through my connections with Misu, she introduced me to her friend Mia, who grew up in a small town in southern Germany and then moved to Berlin to attend the Korean studies programme at Frei University. Mia discusses how the intellectual spaces of university and the city helped her to develop a distinctly diasporic positioning in the following:

I didn't really have Korean friends at home. It started here when I moved to Berlin. It was great. [In the program] we shared the same experiences and we talked a lot about it, being half Korean and half German, about how we felt. We shared the same interests too and it was really comfortable to get to know people with the same background as me and I started to be proud to be part of two cultures and to know both sides. It was a great time to be here and to be develop these things here. This is why I decided to stay here in Berlin. I really like living in Berlin. It's a big city, where you can be just yourself and you don't have to fit into just one group. Nobody thinks you're strange because you act like you do. Because I don't want to choose. I want to be okay with both sides of my family and accept both my sides and identities. Both sides have their advantages and disadvantages and yes, of course, I would like to have the advantages of both.

This diasporic positioning was developed through her sense of belonging in Berlin. Mia traced this to a location where she began to construct multiple forms of identification and belonging. Mia narrated how these social and intellectual spaces gave her the tools to challenge and critique the strict identity binaries dominant within a monocultural society. Mia's statement that you "can just be yourself” in Berlin, without having to explain your origins suggests that the diasporic broadening of community and affiliation enabled her to see herself through an alternative set of identifications.

Ben, whom I met through a Berlin-based cultural organisation for second-generation Korean diaspora called Korientation, is 30 years old and currently lives in Berlin. He talked to me about the difficulties of growing up in Turkey as someone who was multiracial, whose mother is Korean and whose father is Turkish. Ben moved to Berlin when he was 19 years old to go to a university and has been living there ever since.

Here in Berlin, I guess I'm living in an academic bubble and because of where I'm working that are quite international, so I don't have to think about being different. I have some Asian colleagues as well. When I was here as a student, I also didn't - I was never asked about it [being mixed] or anything. I don't have any experience actually. But living in Berlin, I had a Korean girlfriend while I went to university and she was from Korea and then came to study here. I mean, I feel Korean and I would say that I identify as Korean. But now, I grew to also really not care so much about feeling this or that, like I have to be Korean or Turkish. Now I don't care so much, and I really like that.

Brown (1998) argued that diasporic resources are constructed through places and people. Ben's narration of his time at university and living in Berlin exemplifies how these resources depend upon the social spaces and diasporic encounters that were made possible through the space of the university, which drew together many people who had multiracial and diasporic backgrounds and also had a scholarly interest in such areas. Here, Ben's thoughtful observations of his growing diasporic consciousness is a clear example of Brah's concept of diaspora space, where there is a blurring of the boundaries between racialised minorities and the White majority that challenges "native" claims of belonging over other groups. 
However, Ben's insights extend Brah's concept of a diaspora space to question the importance of the "we" in the construction of a diasporic community, with the desire to feel connected to those communities that are geographically dispersed in the diaspora. To put it another way, Ben's response is a powerful example of his emplacement in Berlin, as a process that signals a growing awareness and negotiation of multiple identifications, that also gave him the opportunities to meet and make meaningful diasporic connections with people, such as with his Korean girlfriend, with whom he shared ethnic affiliations.

Equally, as Ben recognises, this process is also about extending his identity beyond the national and ethnic boundaries and rejecting such ethno-specific affiliations and connections, which has enabled him to push back against a narrowly defined understanding of community. In doing so, this reconstruction of community has enabled Ben to shift his own embodied sense of a racial and ethnic self.

Similarly, Jonas, 30 years old, here discusses how his move to a city enabled him to grasp a more complex notion of place and community and how these were instrumental to his understanding of his own de/racialised position and a sense of belonging. Jonas, who currently lives in London, was raised in a small town outside of Frankfurt. However, in moving to Frankfurt for his last two years of high school, he encountered a different set of networks:

I went to a suburban high school and it was a far cry from the city. There were a few people with a migration background, but they were not visible. And it was so small-minded, and then I transferred to a high school in Frankfurt for my last two years, which is a fairly international city and then I met people from everywhere and that was such a change! There for the first time, I was exposed to people from everywhere. In my grade were two Korean girls and so, it was the first time, I had a sense of belonging and maybe that was the first time I felt like it was something I should appreciate and make part of who I am.

For Jonas, Ben, Mia and Misu, the development of these ties highlighted the importance of the local and transnational sense of place and people as critical resources from which to draw inspiration and strength. For them, the development of these critical resources was made possible by moving to places where these resources were made readily available. These resources provided the means to destabilise the strict, opposing racialised binaries of "white" and "Asian".

Brah's theorisation of a diaspora space is useful for understanding the importance of non-essentialist ways of creating ties within a community (1999). Brah referred to Haraway's phrase, the "self-critical practice of difference", and discussed how it is constructed in and through political and intellectual work (1992, 87). For Misu, Mia and Ben, the university offered this intellectual space that allowed for a critical practice of difference that is the hallmark of diasporic consciousness. Through this practice, these students constructed forms of identification that were also based on not being the same. Brah's concept of diasporic space and the significance she places on the practice of difference offer a way of thinking about how these affinities are made in a way that can transcend identifications of ethnic sameness. Brah $(1999,19)$ makes critical distinctions between categories such as "ajnabi" (a stranger who might one day be a friend), "ghair" (total stranger) and "apna" (one of our own). Through a critical practice of difference, the category of "apna", of those who are considered one of "our" own, expands to include those who may start out strangers but ultimately find the promise of friendship and intimacy that are not based on being homogenous. For Misu and Mia too, the connections they made in that space held the promise of friendship and intimacy, that of "ajnabi" and not of "ghair".

Moreover, the focus on the places of settlement within Brah's theorisation of diaspora space has meant that the framing of diaspora is primarily understood to happen in the present tense of the "here" and is embedded in the local. However, in the case of the second-generation diaspora who are multiracial, an outward focus on the "there" of transnational spaces, connections and communities that are made possible through Berlin is what drives and informs this diasporic consciousness.

Furthermore, Brah's conception of diaspora space focuses on the potential of diaspora to impact the ways in which people, natives and diasporeans relate to one another. However, evidenced by my conversations with Misu, Mia, Ben and Jonas, diasporic identifications for those who are of the secondgeneration diaspora and who are also multi-racial show how diaspora can change and how they relate to and construct their sense of selves, shifting their embodied conceptions of difference and sameness. 


\section{Diaspora and refocusing on the "elsewhere"}

Sofia, 32 years old, had lived in Berlin and recently relocated to London, which is where I met her. She was born in Berlin, but she and her parents moved to a small village in northern Germany when she was 8 years old. Sofia in the following narrates how learning Korean was a life-long journey that allowed her to build new affinities with people and places. It especially allowed her to develop deeper relationships with the important people in her life.

I would only ever hear Korean when my mother was arguing with my father and she would yell at him in Korean, so I always thought it sounded so angry. So, for the longest time, I didn't want to learn it. I came to understand and appreciate it later in life. After I broke up with my boyfriend and was living in Berlin, my mom said "hey, to take your mind off of things, I've booked us a trip to Korea!" So, I went to Korea for the first time with my mom. I met my uncle for the first time and I was so humbled. I felt like we really connected. I then enrolled in this super intensive course at Yonsei University. Took my suitcase and moved there to learn Korean. I found an apartment near Yonsei. But basically, being in Korea was life-changing. Basically, part of me is really proud to be a part of the German culture but also, I am proud of being Korean too but couldn't really talk about it or be proud when I was growing up. I always grew up just only being able to talk about being German and the other part never got recognised in a good way. One of the things I'm most grateful for is that it helped me to finally understand my mother and develop a close relationship with her. It's not like my mom doesn't know German, but do you ever think that people are different people with different languages? I think there are so many things also that I didn't know about my mom and wanted to ask her about all these things about how she was when she was young, and learning Korean helped me to ask these questions and get answers from my mom about that side of her life. I mean, it opened up a whole new side to my mom for me that I just never knew existed.

Campt's work on diaspora highlights how diasporic resources are about actively constructing a set of relations for specific purposes, and central to such relations are "complex forms of desire and longing" (2002, 97). Campt's work focussed on the Afro-German diaspora and the ongoing tensions within the relations and politics of diaspora. Her study is useful here in highlighting the central role of this desire and longing in the construction of diasporic consciousness.

Sofia's narration of her journey towards learning Korean and living in Korea exemplifies a very active building of relations that also reflect the complexities of diasporic longing and desire. The initial rejection of Korean language, family and cultural knowledge eventually led to her embrace of language, culture and family later on in her life that she described as "life-changing". Similarly, Sofia's descriptions of first going to Korea with her mother and then moving to Korea suggests a different way of thinking about these transcultural, transnational affinities that Sofia formed. First, these are complex affinities and relationships that Sofia eludes to in her interview. The affinities and identification came through personal struggle and long-term dealing with social isolation and alienation growing up in a small town in Germany as one of the only multiracial families in town. Sofia's childhood and adolescent refusal to learn Korean reveals the tensions of being multiracial in a monoracial, white-dominant German society and the displacement she must have experienced.

Christou locates the process of diasporic belonging in and through what she calls "place-based emotional attachments" $(2011,249)$. Here, Sofia's narrative of her development of a diasporic identity is tied directly to her ability to make a life elsewhere, in other places, such as when she moved to Korea. Moreover, this sense of belongingness is, as Christou insists (2011), a "paradox" of both identification and contestation. In Sofia's narration of this discovery, coming to terms with her "belongingness" entailed an initial rejection of certain forms of Koreanness and an eventual embracing of this side in later years that developed alongside an increasing sense of locatedness and place-based identification that came with visiting Korea, locating family and then eventually living there for a time.

Moreover, developing cultural knowledge and building cultural competencies in Korea helped her to develop empathy and understanding of other people in her life, namely, her Korean mother. Sofia's process of developing a diasporic identity shows how this knowledge becomes a critical tool to unlock alternative ways of knowing others. It connects ways of knowing to a broader set of social relations and the importance of having cultural memory, histories and consciousness in order to connect and empathise with others. As Campt (1993) argued, the role of cultural memory within accounts of diasporic identity- 
making is noteworthy because it shows how cultural resources (music, culture and objects) are drawn upon at particular times in particular spaces as sources of inspiration for building communities and in remaking cultural identities. Ultimately, Sofia's desire to know more about Korean culture was wrapped up in her desire to belong to a community. It was also about reclaiming this identity that she felt was never something that she could claim as part of who she was. Sofia's story reflects the stitching together of these multiple identifications and the desire to hold these seemingly contradictory segments of the self - the German and the Korean selves - together. Getting to know these different and earlier unknowable sides to her mother reflects this reclaiming of her identity.

The following story Sofia tells of "becoming" American illustrates how this developing desire for an "elsewhere” precipitated a move towards new places.

\begin{abstract}
At the end of tenth grade, I went to America as an exchange student $1 / 4$ It was the first time I realised how badly I wanted to be like one of them. I pretended to be American to the group and that's kinda how I sound American now $1 / 4$ I was very determined to not go back to Germany. When I went to America and I was at university, I was one of so many and it was so international. I just felt really comfortable. Whereas when I was growing up in Germany, everyone knew me. You know, I never missed Germany. I've lived in many places, but I've never missed there. But I miss America. I've made it my home and maybe that's wrong.
\end{abstract}

Here Sofia talks about her longing for the "elsewhere" (Hall 2004) when she was growing up in Germany and how migrating to America represented what was a "horizon of possibility" (Ellis 2015). In part, wanting to be American was about asserting her desire to not be German. The disavowal of her Germanness in part stems from the fact that she was always made to feel visibly different, alienated and "other" in her small German town. When she returned to Germany, there she discovered that her time abroad in America cemented her syncretic identity and armed her with the cultural and material tools to navigate her position as an outsider and as someone "in-between".

\title{
5 On not being “German" and challenging racial authenticity
}

In Germany (and elsewhere), it is still the widely held belief that one cannot "belong" or identify as German and also of elsewhere (Haritaworn 2009; Nandi and Spickard 2014). While claims to a racial and ethnic authenticity are negotiated by many people of colour, those who are multiracial are also even more suspect because of the perceived ambiguity of their bodies and the threat of destabilising established racial categories. Therefore, multiracial people often have the double burden of having to prove their right to claim belonging to a group and are often considered as people "in-between" (Haritaworn 2009; Haraway 1997).

As Mia said, "I always felt very German as a child, but I think I was never accepted as a German from German society because I didn’t look German. That was very hard for me”.

The conversation of Jonas, given in the following, is another example:

A: Do you ever label yourself as mixed?

J: Yes, all the time! If someone asked me if I feel comfortable $1 / 4$ I never know what to say $1 / 4$ So you know how there are people who say "yeah, I'm British or American" but I never knew what to say. I kinda feel European. Yes, I have the Korean part, but I grew up German and there were so many powerful influences around me that were simply German but it's not something I like or am proud of, so I don't feel German, but I don't feel entirely Asian either. I like that liberty and I don't like being pushed into that corner. It's much more transient than that so don't even try. Racially, I don't think about it. I think I'm very not aware of my physicality sometimes. I mean, who really thinks that much about what they look like? I don't really think I look fairly Asian for a mixed guy, so I wouldn't have a certain word to describe it $1 / 4$

Germany does not have a way of talking about race, despite the fact that race very much determines whether one is seen as an insider/German or whether one is seen as an outsider (Nandi and Spickard 2014). Visible markers of racialised difference often determine whether one is considered to be authentically German. Jonas' statement points to the fact that in one sense, he is not always made to feel like he is racially "Other". 
So, despite not being able to see himself as someone who is racialised as different, he does sense that he is often made to feel like he was perceived as "different" by other Germans. His reluctance to identify as German points to the fact that despite not being dissected and categorised as racially "Other", he also cannot or often has not been able to claim authentic "Germanness".

Jonas' ambivalence to claim a national or local identity, paired with an awareness of the difficulties of categorising his position, reveals how he is deeply aware of the inadequacies of racial categorisations that call attention to a singular identity and how his identity is contingent upon different times, relations and contexts. Calling himself a European or an Asian allows for these multiple identities to exist at the same time without fragmenting his sense of self. Campt refers to this ability to be able to choose a variety of cultural and ethnic identifications as a form of "agility" or "versatility" $(1993,115)$. This works as a "mode of survival" for people of colour in Germany who face racism and suspicion over their racial classification. So, in being able to navigate and strategically shift his positioning between various labels (European, Korean, Asian), Jonas acknowledges this manoeuvring as a form of "liberty" that allows him to sidestep racialised binaries. It is important to note that Jonas cannot entirely avoid such racialised categorisation, even if he struggles to articulate where and how he is racialised. His awareness of "passing" for white also suggests that his racially ambiguous features allow for such liberties to be had.

Sofia continued her story of returning to Germany from the US, illustrating how this manoeuvring and agility extended to the construction of her extended identities that were multiracial, diasporic and transnational.

When I moved my life back to Germany, I went first to my little home town. Then I went to Berlin and got a job as a designer. But then it became very apparent to me that I think like an American and not a German person. The interesting thing is even now, people will see me as American and speak to me in English and not in German and I let them think that. People assume I spoke English because I don't look German.

Sofia revealed how she strategically presented herself as a non-German and an outsider in a way that allowed her some control. This was a manoeuvre that gave her the ability to avoid the predictable questions or comments on her racial and cultural assignment. The insistence on proving a racial authenticity and the pain and denial of the recognition that mixed Germans face result from the conflation of German national identity with a racialised white identity. This became a way of turning that often painful misidentification on its head.

\section{Metropolitan paradox}

Mia continues by discussing how racism often was something that was enacted by other non-whites from migrant backgrounds. She said:

The thing is, I get racist phrases from people who are not [white] German, especially here in Berlin. If I heard something stupid or racist, it's often from Turkish people or people with migrant backgrounds as well. I always ask myself so why are you talking like that because we're in the same boat and experience the same problems! Ben discusses his own coming to terms with his sense of identity, which involved having to negotiate the constant questioning of his mixedness and the suspicion or reluctance to accept his claims to belonging:

\footnotetext{
Actually, I always identify as a Korean because everyone identifies me as Korean. I have a Korean face. A lot of people comment on how I should identify, and they say that if my father is Turkish, then I'm Turkish. But it's hard to identify as Turkish because when I grew up, I faced these micro-aggressions, so I think it's clear they don't accept me as Turkish, so why should I identify with that? That's definitely another reason why I identify as a Korean. I feel more $1 / 4$ it's just something that I feel more comfortable to say and part of it is that when I say I'm Turkish, and then people will always ask me about it and I don't want to go through it all.
}

Brah (1999) argued that a critical practice of difference facilitates horizontal modes of alliance and offers the promise of friendship and intimacies with people who are not ethnically the "same". At the same time, 
these categories of "stranger", our "own" and "others" speak to the ways that othering can happen where an irreducible difference remains, despite sharing things in common such as political views or even, as in Mia's and Ben's cases, being racially marginalised in ways that are similar.

Brah's concept also speaks to the ways that these racialised hierarchies work in cities like Berlin and where histories of migration, class and race intersect to position groups differently. White (1997) argues that to an extent, the Turkish occupied a unique place within the German society that suggested both insiderness and outsiderness, in contrast to other racialised, non-German ethnic groups who were seen as more straightforwardly "foreign" and "Other". Moreover, in the immediate aftermath of East and West German reunification, it has been argued that the Turkish were sometimes considered to be "co-citizens" or at least Auslanders with more local and long-term presence than newer groups, particularly the new East Germans (1997).

At the same time, these hierarchies are also mutable and relational. Highly racialised hierarchies always serve to separate, mark out and differentiate diasporic communities. Whereas, compared to Eastern Europeans, the Turkish may or may not be perceived as being "more" or "less" German, in comparison to other diasporic communities, Turkish and Russian diasporas are perceived as being less "integrated" and assimilated. In more recent years, Muslims have become hypervisible minorities. Muslims' "lack" or failure to integrate has become part of the normative public and political discourse across Europe, including Germany.

On the other hand, the "model minority" stereotype of the "successful", "hardworking" and "industrious" East Asians were and are still prevalent in Germany and effectively used to distinguish and shame other minorities, such as the Turkish or Eastern Europeans. Moreover, Asians are considered to be the "good" minorities because they are perceived to have integrated successfully. What underpins this belief is the cultural logic that Asians are supposedly, culturally speaking, more similar to Germans. These racialised hierarchies (often masked as culture) that position and pit minorities against each other (and is often internalised by minorities) reflect the complex ties of everyday racisms and forms of racialisation that are affixed to bodies in intensely multicultural and convivial spaces. These racial tensions are manifested in the racialised encounters that occur in a multicultural city like Berlin on an almost daily basis. Mia's and Ben's account of racism and disavowal, particularly by those who are themselves non-white, suggests how difficult it can be to form alliances and communities of solidarity based on similar experiences of racism and exclusion from mainstream white German society. Instead, often this "metropolitan paradox" (Back 1996) of both racism and conviviality is intensely real in these kinds of encounters where those who are marginalised are pitted against each other and compete for scarce resources.

\section{Conclusion}

In this article, I have argued that there needs to be a way of discussing how multiracial people develop and draw upon a range of diasporic resources to help them negotiate a more plural, multiply located sense of selves. These resources enabled my participants to circumvent and challenge the strict binaries of being German/non-German based on essentialist notions of belonging. I have shown how these diasporic resources have been located and grounded in places, community spaces and with people and how everyday multiculture and the existence of diaspora spaces in the city made it possible for my participants to develop and activate their diasporic resources.

The construction of diasporic spaces in the city allowed for participants to understand the complexity of such entanglements between people and blurred the lines that exist between "native" and diasporean, insider and outsider. The stories of migrating to Berlin and meeting people, many of whom were not Korean, introduced a diasporic sense of sameness in and through difference or the "critical practice of difference" (Haraway 1992). This practice of difference was a crucial sign of the lived aspects of multiculture, of a conviviality that is the overlapping of sameness and difference (Gilroy 2005). Moreover, it also facilitated alternative modes of identification, in that it enabled my participants to frame themselves differently, not 
just through the prism of racial binaries of "white" or "non-white". It also suggested that the imagining of diasporic consciousness, as well as the complex desires and longing that help to construct such diasporic identifications, is rooted or oriented not only in the here and the now of local spaces and connections but also, crucially, in a desire for an "elsewhere". For my participants, this manifested in journeys and in relationships outside the city and nation, often taking them to Korea, the US and the UK.

Being multiracial also means that my participants had to negotiate and withstand the violence of these "what-are-you?" moments in an effort to have people discover their racial "truths". Being perceived as a mixed race also came with its baggage and privileges, where most study participants benefitted from being able to manoeuvre themselves in ways to avoid being racialised as "Other". They were able to utilise their diasporic and transnational resources to claim an outsiderness that afforded them more privilege than being a marginalised ethnic/racial minority.

The city was also simultaneously found to be as racist as it was convivial. The multicultural city is also a place of multiple tensions, made more difficult because race is under erasure and acts of racism then are not allowed to be named in Germany. Therefore, this article highlights how these diasporic resources and a critical practice of difference provide ways of challenging racialised essentialisms and forms of authenticity. However, racism is also always part of metropolitan everyday, despite the creative ways that my participants resist and combat these essentialisms in their daily lives.

\section{References}

Alexander, C. 2010. Diaspora and hybridity (pp. 487-507) in Solomos, J. and Collins, P.H., 2010. The SAGE Handbook of Race and Ethnic Studies. SAGE Publications.

Alexander, C. 2017. Beyond “The 'diaspora' diaspora”: a response to Rogers Brubaker. Ethnic and Racial Studies, 40 (9), pp. 1544-1555

Anthias, F. 1998, 'Rethinking social divisions: some notes towards a theoretical framework', Sociological Review, 46 (3), pp. 505-535.

Aspinall, P. and Song, M. 2013. Differential Ethnic Options? In Mixed Race Identities (pp. 50-77). London: Palgrave Macmillan. Back, L. 1996. New Ethnicities and Urban Culture. Routledge, London

Blunt, A. and Dowling, R. 2006. Home (Key ideas in geography). Abingdon: Routledge.

Brah, A. 1996. Cartographies of diaspora. London and New York: Routledge.

Brah, A. 1999. The scent of memory: strangers, our own, and others. Feminist Review, 61(1), pp.4-26.

Brown, J.N. 1998. Black Liverpool, Black America, and the gendering of diasporic space. Cultural Anthropology, 13(3), pp.291325.

Campt, T.M. 1993. Afro-German cultural identity and the politics of positionality: contests and contexts in the formation of a German ethnic identity. New German Critique, (58), pp.109-126.

Campt, T. 2002. The Crowded Space of Diaspora: Intercultural Address and the Tensions of Diasporic Relation. Radical History Review, 83(1), pp.94-113.

Campt, T. and Thomas, D. 2008 Gendering diaspora: transnational feminism, diaspora and its hegemonies. Feminist Review, 90 (1) pp. 1-8.

Christou, A. 2011. Narrating lives in (e) motion: Embodiment, belongingness and displacement in diasporic spaces of home and return. Emotion, Space and Society, 4(4), pp.249-257.

Ellis, N. 2015. Territories of the Soul: Queered Belonging in the Black Diaspora. Duke University Press.

Eckert, P. 2006. Communities of practice. Encyclopaedia of language and linguistics, 2(2006), pp.683-685.

Ehrkamp, P. 2005. Placing identities: Transnational practices and local attachments of Turkish immigrants in Germany. Journal of Ethnic and Migration studies, 31(2), pp.345-364.

Fortier, A.M. 2003. Making home: queer migrations and motions of attachment. In Fortier, A.M., Ahmed, S., Castañeda, C. and Sheller, M. (eds.) (2003) Uprootings/Regroundings: Questions of home and migration. Berg.

Gilroy, P. 1987. There ain't no black in the Union Jack. Routledge.

Gilroy, P. 1993. The Black Atlantic: Modernity and double consciousness. Cambridge Harvard University Press.

Gilroy, P. 2000 Between camps: Nations, cultures and the allure of race. New York: Routledge.

Gilroy, P. 2004. Postcolonial melancholia. Columbia University Press.

Green, S. 2004. The politics of exclusion: Institutions and immigration policy in contemporary Germany. Manchester University Press. 
Hall, S. 1990. 'Cultural identity and diaspora' in Rutherford, J. ed., 1990. Identity: community, culture, difference (pp. 9-27). London: Lawrence \& Wishart.

Hall, S. 1992. The question of cultural identity. Modernity and its futures, pp.274-316.

Hall, S. 2004, Unpublished interview with Bill Schwartz, pp. 4-5.

Haraway, D. 1992. Ecce homo, ain't (ar'n't) I a woman, and inappropriate/d others: The human in a post-humanist landscape. in J. Butler and J. Scott (eds) Feminists theorize the political, New York: Routledge, pp.86-100.

Haraway, D.J.1997 Modest-Witness@ Second-Millennium. Female Man-Meets-OncoMouse: Feminism and Technoscience. Psychology Press.

Haritaworn, J. 2009. Hybrid Border-Crossers? Towards a Radical Socialisation of 'Mixed Race'. Journal of Ethnic and Migration Studies, 35(1), pp.115-132.

James, M. 2016. Diaspora as an Ethnographic Method: Decolonial Reflections on Researching Urban Multi-culture in Outer East London. Young, DOI: 10.1177/1103308815618138.

Kalra, V. Kaur, R. and Hutnyk, J. 2005. Diaspora and Hybridity. Sage.

Mitchell, K. 2003. Cultural geographies of transnationality. Handbook of cultural geography, pp.74-87.

King-O'Riain, R.C., Small, S., Mahtani, M., Song, M. and Spickard, P. eds. 2014. Global mixed race. NYU Press.

Mannur, A., 2007. Culinary nostalgia: Authenticity, nationalism, and diaspora. Melus, 32(4), pp.11-31.

Martin, P. 1994. Germany: reluctant land of immigration. Controlling immigration: A global perspective, pp.189-225.

Nandi, M. and Spickard, P. (2014) 'The Curious Career of the One-Drop Rule: Multiraciality and Membership in Germany Today' in King-O'Riain, R.C., Small, S., Mahtani, M., Song, M. and Spickard, P. (eds.) 2014. Global mixed race. NYU Press.

Parennas, R. and Siu, Lok C. D. 2007 'Introduction' in Parennas, R. and Siu, Lok C. D., (eds) 2007. Asian Diasporas: New Formations, New Conceptions, Stanford University Press

Pierre, J. “'I Like Your Colour!' skin bleaching and geographies of race in urban Ghana' Feminist Review, 90 (1) pp. 9-21. Walter, B. 2001. Outsiders Inside: Whiteness, Place, and Irish Women. Psychology Press.

White, J.B. 1997. Turks in the new Germany. American Anthropologist, 99(4), pp.754-769.

Wilpert, C. 1998. Migration and informal work in the New Berlin: new forms of work or new sources of labour? Journal of ethnic and migration studies, 24(2), pp.269-294. 